\title{
CONCEPÇÕES DE DOCENTES DA ENFERMAGEM SOBRE A POLÍTICA DE SAÚDE DO HOMEM
}

\author{
Luiza Helaehi \\ Nicássia Senhorini Magalhães \\ Luiz César Gerotto Junior \\ Clarice Santana Milagres \\ Discentes do Curso de Enfermagem do \\ Centro Universitário Hermínio Ometto - FHO Uniararas
}

INTRODUÇÃO: A Política Nacional de Atenção Integral à Saúde do Homem (PNAISH) consiste em ações e serviços voltados à população masculina. $O$ Ministério da Saúde, em conjunto com as esferas estaduais e municipais que compõem o Sistema Único de Saúde (SUS), compreendeu que para melhorar os padrões e qualidade de vida era essencial desenvolver cuidados específicos para os homens jovens e adultos. OBJETIVO: O estudo teve como objetivo analisar a capacitação de docentes do curso de enfermagem sobre a Política Nacional de Atenção Integral à Saúde do Homem (PNAISH). O projeto foi aprovado pelo CEP sob parecer de número 1.781.271. METODOLOGIA: Tratase de uma pesquisa descritiva de abordagem qualitativa, realizada através de uma investigação com os docentes, onde os dados foram coletados por meio de um questionário. Após a coleta, os dados foram categorizados para a análise dos resultados. RESULTADOS: As categorias analisadas foram em relação aos conhecimentos fundamentais acerca das políticas públicas de saúde no SUS e a inserção da PNAISH; a importância da execução da política nacional de atenção integral à saúde do homem; a atuação do enfermeiro diante da PNAISH; as práticas pedagógicas em sala de aula sobre a PNAISH. CONCLUSÃO: Este artigo buscou conhecer a percepção dos docentes sobre a PNAISH e pode observar que a formação acadêmica dos alunos está diretamente relacionada ao conhecimento transmitido pelos docentes.

Palavras-chave: Saúde do homem. Docentes. Educação em enfermagem. 